\title{
The Research on Integration of Music and Technology in Guzheng Teaching
}

\author{
Shanxia Peng ${ }^{1}$ \\ ${ }^{1}$ Linyi University, Academy of Music, Linyi, Shandong, 276005 \\ hunter2011@foxmail.com
}

Keywords: Guzheng Teaching; Music; Technology

\begin{abstract}
In recent years, the integration of "music" and "technology" in Zheng teaching problem gradually attracted people's attention. In guzheng teaching process, traditional teaching methods can not meet the needs of modern society, for which should be gradually optimized in zheng teaching methods. Based on the analysis of practical problems exists in guzheng teaching, this paper introduces the method about how the "music" and "technology" should integrate in zheng teaching process.
\end{abstract}

\section{Introduction}

In recent years, with the continuing reform of teaching, zheng teaching gradually integrated into classroom teaching. In guzheng teaching process, the fusion of art and technology of music is essential, therefore in order to improve zither performances art show, requiring teachers to pay attention to students in guzheng zither technology teaching process. In addition, the current status quo, the teachers in the teaching process guzheng others because of its focus on training students skills, thereby ignoring the importance of the integration of art and technology, resulting in students can not fully demonstrated in Guzheng zither process The most natural charm. In the modern teaching process, teachers will be repeated according to the conventional method of playing the standardization of training and level of student possession, after a long period of training, the students accurately grasp the playing skills. However, since the students while playing standardized method ignores the cultivation of students' artistic content, resulting in students through zither music appreciation can not feel their culture. Zither music carries the nation's knowledge structure and artistic heritage, and therefore to guzheng art teachers in the teaching process, the students should pay attention to the imagination, prompting students to master standardized method to play at the same time, also in-depth understanding of the profound meaning of zither music, and ultimately the performance effect "technology" and "art" of integration, improve the zither music artistic charm.

\section{The Reason to Promote Integration of Guzheng Teaching Music and Technology}

Make the Classroom More Interesting. Guzheng teaching music and technology integration of teaching, teaching environment can be optimized to a certain extent, improve classroom teaching interesting. China's traditional guzheng teaching methods are simple and rather dull teaching content, thereby causing students in the classroom learning guzheng gradually exhibit a negative attitude towards learning. For this, and vigorously promote the teaching methods of music and technology integration implementation is very necessary. Only in this way, students can create a good learning environment, promote student in this environment can improve their enthusiasm for learning, but also threw himself into learning activities. Traditional teaching methods have technology-based culture, a certain lack of cultural activities. Thus in the classroom zither music and technology integration, and requires teachers to students to attend regularly scheduled cultural events corresponding to mobilize students' enthusiasm and initiative.

Promote the understanding of music. Music and technology integration zither teaching methods may also deepen students' understanding of music to a certain extent. However, in the music and technology integration in teaching background, requires teachers should take appropriate 
measures body language into the language of music, for example, in explaining the "Moonlit Night" in the process, you can achieve the emotional body language and music perfect fusion, and ultimately to better play the music itself connotation, infection zither music appreciators. At the same time, encourage students through body language analysis to better understand the meaning and significance of zither music carried. Zheng classroom and in the teaching process, teachers should pay attention to mobilize the initiative of students, thus contributing to the zither music students in the learning process, through the literature to find other ways of understanding the story behind the music, and to deepen their own understanding of the nature of the music.

\section{Promote the Integration of Music and Technology}

Traditional Night Moon is a traditional Chinese art an essential part occupies an important position. Zither played music most of the traditional music, we know there are "Mountain and Flowing Water", "Moonlit Night", "Boats" and so on. These famous masterpieces still plays an important and irreplaceable role in the art world. In Zheng's learning process, we should learn to draw nutrients in the traditional culture. Only by fully understanding the traditional culture and art zither can really track interpretation zither, grasp the essence of the music section, music and technical mastery. At the same time, we have to understand the technology on a solid foundation and interpretation of music, absorb nutrients from the traditional music but also enable us to further enhance our playing technique, these two are complementary and mutually reinforcing, therefore, to learn traditional music will essential.

Further strengthen the body language has always been one of the zither played an important part, but a lot of people in the process of playing often overlook the importance of body language, or learning rigid body language, resulting in a performance during rigid. In fact, the body language is a form of expression of music both at the same time, it also belongs to a technology, as a technology language, how to utilize your own body language is extremely important, however, from a large extent, Body language is an important way of musical expression, which is the natural expression of emotion, but the body language can contribute to the perfect combination of music and technology, so that people better understand the body language of music itself, therefore, is not only the body language teaching guzheng The important part is more important is how to properly use body language, master the correct method of body language to express the promotion of music and technology has a vital role in the natural fusion.

\section{Specific Ways to Improve Teaching of Zheng}

Technical Basis of Guzheng. In order to achieve the integration of teaching zither music and technology, it requires teachers in the teaching process should first focus on training technical base of students. Perfect zither music art exhibits and technical basis zither player are closely related. Therefore, in order to better educate students of music and technology integration performance concept, requiring teachers to pay attention to arrange students in the classroom teaching process guzheng related exercises in order to improve student technology base to some extent. For this may be from the following aspects: First, we should strengthen the training of students fingering, encourage students while playing zither music in superb fingering techniques can be used to interpret the perfect musical content; second, in order to improve the technical basis Guzheng student teachers in the teaching process should focus on training students to form good habits, namely students to develop scientific training program, students are required on the basis of the training process according to the provisions of the plan. In the long-term training program, training students to develop good habits, and ultimately to better improve their technology base; and third, teachers should communicate effectively with parents and ask parents also pay attention to cultivate good living zither beginners Training habit forming, and ultimately to provide students with a good learning space, and constantly improve their technology base.

To Cultivate Students Good Learning Attitude. Guzheng teaching in modern music and technology integration, teachers should focus on training students to form a good learning attitude, 
students only have a good attitude in order to better study into the learning environment. Attitudes to forme indirectly determine the performance of works of beauty. Thus teachers in the teaching process, we should first correct its attitude towards teaching, students set a good example and encourage students in a good atmosphere can gradually form a good learning attitude. After a lot of practice survey showed that some zither learners during the race there will be failures in performance. For this, largely due to poor student attitude, resulting in an increase in the error rate performance compared with the usual playing of the process, and the degree of skilled operation also decreased significantly. In order to encourage students to always maintain a good learning attitude, teachers in the teaching process guzheng should observe the changing mentality of student performances, and help students to analyze the reasons for poor mentality, and to help students performing in the process of gradually clear psychological barriers, good learning attitude. Ultimately encourage students led by a good learning attitude, and can gradually enhance their musical literacy and basic technology.

Absorb Nutrients from The Music. Guzheng art has been tradition for decades, so its manifestations vary. In the traditional art of playing the zither, guzheng performance mode is divided into different genres way, if the students in the learning process, not its evolution and other aspects of the process and the way of playing in-depth study and discussion, then the student during the appreciation process will be unable to appreciate the charm of folk customs, and can not achieve the best performance techniques. Traditional art is the foundation of modern guzheng zither teaching, so teachers in the classroom teaching process, should pay attention to guide students to absorb nutrients from the traditional zither music, enrich their own artistic sensibilities, which eventually will be better integrated into the modern zither performances, resulting in more performance with unique charm and art. At the same time, students in the learning process guzheng basic technology, but also should focus on learning and understanding of traditional technologies, resulting in learning the traditional art can grasp the essence of the traditional zither performances part, and their integration into the modern zither performances, zither performances possess abundant charm, and ultimately achieve the effect of playing good music and technology integration. For example, in the play "Preface to King" zither music, because its songs full of working people live comfortable, a peaceful dreamy mood. After a day of labor fishermen also marching brisk pace home. This time the picture is a modern city people can not understand that. Thus, in its playing, if the students mastered itself to the traditional music of the nutrients carried into which it will perform works more appealing.

Highlight the Importance of Physical Training in the Guzheng. In the process of teaching music and technology integration, requiring teachers should raise awareness of physical training. Namely Zheng classroom teaching process, should strengthen the importance of physical training in the Guzheng and arrange student on the basis of technical exercises, but also help to strengthen the training of its own limbs, and ultimately enhance the flexibility zither process. Body language is a zither music in a form of expression, but it is also an integral part of technical language, and thus strengthen the flexibility of their own body language learning process in zheng is very necessary. Physical training can make students master the basic techniques to be able to optimize their performance on the basis of skills, but will also promote the perfect combination of zither performances of music and technology. But Zheng teaching physical training, requires teachers to pay attention to guide students on the proper use of body language, prompting students to master the correct body after using techniques to better achieve the integration of technology and music.

To Strengthen Their Understanding of Music. It is an effective way of teaching modern Guzheng music and technology integration in order to strengthen the student's own understanding of the music. For this may be from the following aspects: First, teachers in the course of doing guzheng teaching, we should encourage students to form their own study behavior, thereby promoting student learning, driven by good behavior, through after-school for zither music improve their ability to appreciate music appreciation, but will also deepen their own understanding of music; second, in Zheng classroom, teachers can use multimedia teaching equipment arrange for students to watch the play of others, and then encourage students to watch the performance of the process, 
the skill of playing experience and successful conclusion, final deepen their own understanding of music, pushing the perfect blend of technology zither performances and music. In addition, teachers arrange students enjoy playing other people's work carried out in the process, should require students to summarize the performance of others in the superb place, and ultimately enhance their effective zither performance technology.

\section{Conclusion}

To sum up, in recent years, teaching methods in Zheng teaching "music" and "technology" integration gradually attracted people's attention. In the traditional teaching process, because of its single teaching methods and way, resulting in students' negative attitude towards learning guzheng music in the learning process. Therefore, in modern guzheng teaching, teachers should vigorously promote the "Music" and "technology" integration of teaching methods, teach environment, and create a good learning atmosphere for students, lead students during the show of guzheng music.

\section{References}

[1] Tu-Yong M. "Teach Hand." and "Teaching The Heart" on the Guzheng Teaching A Dialectical Problem. Nanjing Art Institute (Music and Performance), 2013,12 (01): 112- 114.

[2] Wang-Shu L. Thinking of Establishing Scientific Community Guzheng Teaching Mode Specifications. Science and Technology Information, 2014,23 (01): 25-27.

[3] Zhao-Lu Q. Countermeasures Innovation in College Teaching. Chifeng University (Natural Science), 2014,21 (09): 19-21.

[4] Zou Q. Zheng Teaching How to Improve Students' Interest. Education Wenhui, 2013,22 (01): 213-215.

[5] Lu Y. Several Issues Should Be Paid Attention to In Zheng Teaching. Tongren University, 2013,21 (07): 22-23. 